\title{
MECENAS Y FORTUNA DEL PINTOR ANTONIO DE PEREDA *
}

\author{
POR
}

\author{
ÁNGEL ATERIDO FERNÁNDEZ
}

\begin{abstract}
This paper presents an overview of the life and works of Antonio de Pereda on the basis of archival documents, many of which remain unpublished. More than anything else, the study demonstrates the close relationship between Pereda's most significant early patrons, D. Francisco de Tejada and Giovanni Battista Crescenzi. This essay also demonstrates the activities developed by the artist besides painting; economical transactions, loans and grain deals - unknown until now-. Out of his codicil and the last wills issued by his second wife, the study presents some unknown art pieces.
\end{abstract}

El pintor Antonio de Pereda representa un caso un tanto atípico, en el conjunto de la pintura en Madrid durante el siglo xviI ${ }^{1}$. Ajeno a los cambios que se dieron a mitad de la centuria para desembocar en un barroco exultante y arrebatado, Pereda mantuvo una trayectoria bastante uniforme y personal. Incluso, entre sus peculiaridades, se le sospecha como el artista analfabeto con mejor biblioteca de su tiempo.

Su fortuna crítica, tanto en su siglo como en la actualidad, lo sitúa entre los artistas destacados dentro del «tono medio» de los pintores madrileños. Hay coincidencia a la hora de tenerlo como figura de importancia y calidad. En cambio, poco se ha hablado de sus "otras fortunas»: la de sus bienes materiales y la que le valió la clientela de la que gozó. En este sentido, se vienen repitiendo mecánicamente los nombres de algunos de sus patronos, desde sus primeros estudios biográficos, atendiendo pocos al significado que encerraba tal mecenazgo. La lectura de nuevos documentos y la revisión de esas noticias ya conocidas, abren paso a un análisis más detenido de varios aspectos de la vida de Pereda.

\section{El primer mecenas: Francisco de Tejada}

Por Palomino y Díaz del Valle conocemos al primer protector del pintor en Madrid: don Francisco de Tejada y Mendoza, del Consejo y Cámara de Castilla. Poco se sabe del discreto mu-

* Agradezco la colaboración prestada por Purificación Ripio, José M. Navas, Dolores Ramos, José M. de la Mano y Jordi Campbell, sin cuya ayuda este artículo no sería el mismo.

1 Diego Angulo y Alfonso E. Pérez Sánchez: Pintura madrileña del segundo tercio del siglo xvII, Madrid, CSIC, 1983, pp. 138-239. Para no extender las notas excesivamente, los datos biográficos puntuales referidos en el texto, de los cuales no haya aportación posterior o se haga nueva, remiten a esta obra. 
seo que a juicio de Carducho atesoraba el consejero en su casa, o de las pinturas originales de grandes artífices que en ella sirvieron de escuela al joven Pereda, según Díaz del Valle. Aunque hoy se puede obtener una idea aproximada de las conexiones y apetencias artísticas de Tejada reuniendo distintas fuentes, alguna de ellas inédita. Es el caso de las pinturas que heredó de su padre, también consejero de Castilla, a la muerte de la segunda mujer de éste, D. ${ }^{a}$ Mayor de Córdoba. En la correspondiente partición de bienes realizada con su hermano D. Félix de Guzmán, canónigo de la Catedral hispalense, a D. Francisco le correspondieron 30 obras $^{2}$. Era un conjunto al uso en la España del momento, en el que predominaban las imágenes religiosas, apenas había cuatro retratos y sólo una pintura mitológica (un cupido). Al no especificarse autorías, poco más se puede aventurar respecto a este núcleo de la colección de Tejada, sino su temática tradicional.

No parece que fuera la herencia la vía por la que el Consejero adquirió sus obras más importantes. Así Pacheco, en su Arte de la Pintura, refiere la existencia de un "Ganimedes» de mano de Giulio Clovio, basado en un dibujo de Miguel Ángel, entre las piezas que poseía Francisco Tejada cuando ocupaba la Presidencia de la Casa de Contratación de Sevilla ${ }^{3}$. Muy elocuente resulta al respecto su testamento, redactado en 1632 y modificado poco antes de morir en $1634{ }^{4}$. En él especifica algunas donaciones de objetos a deudos y familiares, entre los que figura el mismísimo Conde-duque de Olivares. El grueso lo constituyen joyas y obras devocionales sin autor conocido, siendo de destacar legados como las dos imagines de Christo nro. Sr. y nuestra Señora copiadas del ticiano dejados a su hijo Félix, la imagen de nuestra señora con su hijo preciosso de Don Juan de Jáuregui destinada al marqués de Almazán y un christo de marfil obra de Delgado que lega a Melchor de Moscoso, Obispo de Segovia; ésta última debía ser de mano de Gaspar Núñez Delgado, escultor sevillano famoso por sus piezas de marfil.

Otro interesante apartado del documento, en lo que a sus preferencias artísticas se refiere, es el concerniente a la fundación de una capilla en el Colegio Imperial de Madrid. El consejero detalló con precisión las piezas destinadas a su alhajamiento: una Adoración de los Reyes atribuida a Tiziano, un lienzo de San Miguel de autor desconocido y, como imagen del altar principal, el christo grande que tengo en mi oratorio. Este Crucificado es el que, atribuido a Juan de Mesa, hoy preside la actual Catedral de Madrid (Fig. 1). Es más, se cita entre relicarios y elementos de orfebrería el niño Jesús de Bronce de Martínez, sin duda refiriéndose a una obra hoy ignorada de Martínez Montañés. Por último, la obra de arquitectura se había de acabar conforme a las trazas que tengo comunicadas con el Señor Marqués de la Torre, assi en el edificio como en el retablo y altares.

Aunque la capilla no llegó a concluirse según los deseos de su fundador ${ }^{5}$, el solo conocimiento de su planificación es prueba importante de sus preferencias. Varios son los factores que se pueden deducir de lo dicho acerca de la colección de Francisco de Tejada. De una parte, la fuerte presencia del arte sevillano de principios del xviI, caso de Núñez Delgado, Jáuregui, Mesa y Martínez Montañés. Incluido alguno de los elementos manieristas italianos que coinciden en la formación del primer barroco en Sevilla, como es la visión de Miguel Ángel a través de Clovio. Esto es explicable por el propio origen del mecenas, natural de la capital andaluza y partícipe

\footnotetext{
2 Archivo Histórico de Protocolos de Madrid (AHP): prot. 3.975, ff. 1.111-1.114 (26-I-1621).

3 Francisco Pacheco: El Arte de la Pintura, Sevilla, 1649; ed. B. Bassegoda, Madrid, 1990, p. 455. El Ganimedes de Miguel Ángel interpretado por Clovio, fue una de las obras más conocidas del croata, como atestiguó el también miniaturista Francisco de Holanda. Véase Francisco de Holanda: De la pintura antiga (1563); ed. Madrid, 1921, p. 203. Maria Gionioni-Visani: Giulio Giorgio Clovio. Miniaturist of the Renaissance, London, 1993, pp. 107-108.

4 AHP: prot. 6.179, ff. 950-959. El testamento de Francisco de Tejada fue redactado el 24- VI-1632; siendo abierto a su fallecimiento, el 11-XI-1634. Referencia tomada de Janine Fayard: Los miembros del Consejo de Castilla (16211746), Madrid, 1982, p. 347.

5 A. Aterido: "La capilla del Cristo del Colegio Imperial de Madrid. (La contextualización de la imagen en el Barroco)", Archivo Hispalense, en prensa.
} 
del rico clima intelectual de la ciudad. El elemento «localista", convive al tiempo con el venecianismo, encarnado en el propio Tiziano. Huelga incidir en la trascendencia del pintor véneto en el arte del barroco español, a través del coleccionismo Habsburgo ${ }^{6}$. Que un Consejero de Castilla guardara un Tiziano o alguna de sus copias, es nueva prueba del ascendiente que la colección real suponía para las elites del poder. Es éste el ingrediente que mejor asimiló Pereda entre la heterogénea colección que poseyó Tejada, puesto que su colorido depende directamente del mundo veneciano. El resto de componentes, corroboran la presumible formación arcaizante que el joven Antonio obtuvo en casa del Consejero ${ }^{7}$. Incluso, se puede hallar un remoto eco de la escultura de Mesa en la postura escogida por el pintor para el "Crucificado» del Colegio de San Ildefonso, que realizó en 1652 (Fig. 2).

\section{Giovanni Battista Crescenzi}

Más decisivo para Antonio de Pereda resultó el trato entre Tejada y el Marqués de la Torre, Giovanni Battista Crescenzi, a cuya protección pasó seguidamente. Superintendente de Obras Reales y auténtico "factotum» de las realizaciones artísticas de los primeros años del reinado de Felipe IV. Su elección para hacerse cargo de la Capilla Tejada, trae nuevamente a colación su supuesta actividad constructora, presumida tradicionalmente en obras como el Panteón de El Escorial, cuyo grado de intervención es hoy ampliamente contestado. Cuando menos, creo que se le debe sospechar un mínimo conocimiento de la proyectiva arquitectónica, dado que se le encomiendan retablos y edificio. Como en el citado caso del Mausoleo Real, la obra se concluyó años después de la muerte de Crescenzi, no sabiendo hasta qué punto sus planes fueron respetados. Desde luego, este encargo del consejero pone de manifiesto el vínculo existente entre los dos primeros valedores del joven Pereda en la corte.

Pereda halló en Crescenzi, y esta afirmación ya es tópica, una personalidad bien distinta, que le marcaría mucho más en sus planteamientos artísticos. Aunque Francisco de Tejada también pintaba, puesto que Carducho lo incluye entre los personajes ilustres que practicaron ese arte, la formación artística y el bagaje intelectual del noble provenían del refinado ámbito italiano. Ya no se trataba sólo de un coleccionista de envergadura, él mismo era un artista multidisciplinar, con conocimientos en diferentes campos y, lo que es más importante, con poder decisorio en la política artística del reinado. Como es sabido, no fue casualidad que Pereda figurara entre los escogidos para decorar el Salón de Reinos del flamante Palacio del Buen Retiro. Aun así, el desconocimiento de obras seguras de su mano, ha llevado a cuestionar las fuentes que de antiguo lo reivindican como artista ${ }^{8}$.

Recientemente se ha demostrado que en casa de Crescenzi había diferentes materiales de escultor y piezas vaciadas, lo que refuerza la hipótesis del artista «efectivo» ${ }^{9}$. Esto también explica las escasas noticias existentes que relacionan a Pereda con la escultura. En los años finales de su vida, valoró tallas haciéndose llamar escultor ${ }^{10}$. Incluso, en 1676 se supeditó la ejecución de un

6 Alfonso E. Pérez Sánchez: «Presencia de Tiziano en la España del Siglo de Oro», Goya, 1976, pp. 140-159. Fernando Checa: Tiziano y la Monarquía Hispánica, Madrid, 1994.

7 D. Angulo; A. E. Pérez Sánchez, op. cit., p. 151.

8 Virginia Tovar: «Significado de Juan Bautista Crescencio en la arquitectura española del siglo xviı, Archivo Espanol de Arte (AEA), 1981, pp. 297-317. Luigi Spezzaferro: "Un imprenditore del primo Seicento: Giovanni Battista Crescenzi", Ricerche di Storia dell'Arte, n. ${ }^{\circ}$ 26, 1985, pp. 50-73.

9 Juan Luis Blanco Mozo: "Algo más en torno al equipaje ideológico y material de Giovanni Battista Crescenzi", Actas XI Congreso CEHA, Valencia, 1996, en prensa.

10 Mercedes Agulló: Noticias sobre pintores madrileños de los siglos xVI y XVII, Granada, 1978, p. 127. 
paso procesional, que representaba la Huída a Egipto, a su conformidad con el modelo ${ }^{11}$. Es plausible que Pereda no sólo perfeccionara sus habilidades pictóricas en la mansión del patricio romano, sino que allí también se familiarizara con la escultura. Tal vez Crescenzi ambicionó inculcar a Pereda una idea abierta del artista, a la italiana, que su desaparición evitó que fraguara del todo. No obstante Antonio demostró, siquiera tardía y ocasionalmente, algún conocimiento de dicha técnica.

La relación de Pereda con su mentor hubo de ser muy próxima, puesto que se consideró siempre en deuda con él. De hecho, en su testamento incluyó a Crescenzi entre las personas por las que celebrar misas. Asimismo, él recibió algún legado del Noble ya que sus herederos se disputaron años después lo que por muerte del Marqués $J u^{o}$ Baup ${ }^{t a}$ crezençio y en su vida dio al dho. Don Antonio diferentes estatuas y papeles tocantes al arte de pintor de valor considerable ${ }^{12}$. Pereda se alojaba en casa de su benefactor, en compañía de su hermano y también pintor José, en calidad de criados. Ambos aparecen como testigos, entre otros servidores, de las últimas disposiciones de Giovanni Battista, así como de su posterior apertura y trámites de testamentaría ${ }^{13}$. Por cierto, era sabida la marcha de José de Pereda a América en 1643, fecha en la que se realizaron las informaciones previas a su partida. Hoy se puede añadir que el viaje tuvo como destino final Cartagena de Indias, donde falleció hacia 1648, con la aparición de un poder que otorgó su madre para ocuparse de los bienes dejados por José en la ciudad novohispana ${ }^{14}$.

Al breve momento juvenil de relación probada artista-protector, entre 1632 y 1635 , corresponden unas pocas pinturas documentadas cuya factura y concepción dependen del ascendiente artístico y cultural de Crescenzi; aunque luego se verá el modo selectivo en que Pereda absorbió sus posibles enseñanzas intelectuales. Bastaría citar algunos nombres que se relacionan a él en Italia y España (Pomarancio, Caballiere d'Arpino, Guido Reni, Claude Lorrain, Cavarozzi, Van der Hamen, Juan Fernández Labrador), para apreciar la diversidad de sus gustos artísticos, rasgo por otra parte común al mecenazgo romano de su tiempo ${ }^{15}$. En su estancia española, en cambio, parece que se decantó más decididamente por el naturalismo.

En ese ambiente es entendible la producción de obras de la inmediatez del «Bodegón de nueces» (Fig. 3), que firma en 1634 (col. particular, Bilbao). El tratamiento verista del objeto inanimado se repite en temas menos amables, con idéntico enfoque lumínico, pasando de la simple naturaleza muerta a un tétrico bodegón de calaveras en el primer plano de la "Alegoría de la Vanidad", de Viena (Fig. 4). La objetividad natural se torna entonces en crudeza escatológica, con una intención moralizante bien explícita. La obra, sin fechar, es con probabilidad la que conservó el Almirante Castilla y situable estilísticamente en esta etapa ${ }^{16}$. El tema, habitual en la cultura europea del siglo xVII y connatural al repertorio de Pereda, es propiciado al tiempo por la atmósfera de espiritualidad en que se movía Crescenzi, unido estrechamente a los fundadores de nuevas órdenes religiosas como Oratorianos, «ministros de los enfermos» de San Camilo de Lelis o Jesuitas. Recuérdese que la conversión de San Francisco Borja tuvo lugar con la contemplación del cadáver de Isabel de Portugal, precisamente la esposa del Emperador, presente en la composición.

11 AHP: prot. 10.359, ff. 43-44. Contrato entre Marcos López, alarife, y Manuel Gutiérrez Maestro escultor (20-III1676). El ajuste de la policromía del grupo, también condicionado al juicio de Pereda, en Mercedes Agulló: Documentos para la historia de la pintura española. I, Madrid, 1994, p. 23.

12 AHP: prot. 11.425 , f. 389.

13 V. Tovar, op. cit., p. 300.

14 AHP: prot. 7.476, ff. 156-157. Poder de María Salgado al Dr. Pedro de Medina Rico, Inquisidor Apostólico de Sevilla y visitador de la Inquisición en Cartagena de Indias (21-VII-1648).

15 Francis Haskell: Patronos y pintores, Madrid, 1984.

16 Alfonso E. Pérez Sánchez: La nature morte espagnole du XVIIe siècle à Goya, Fribourg, 1987, p. 110. 

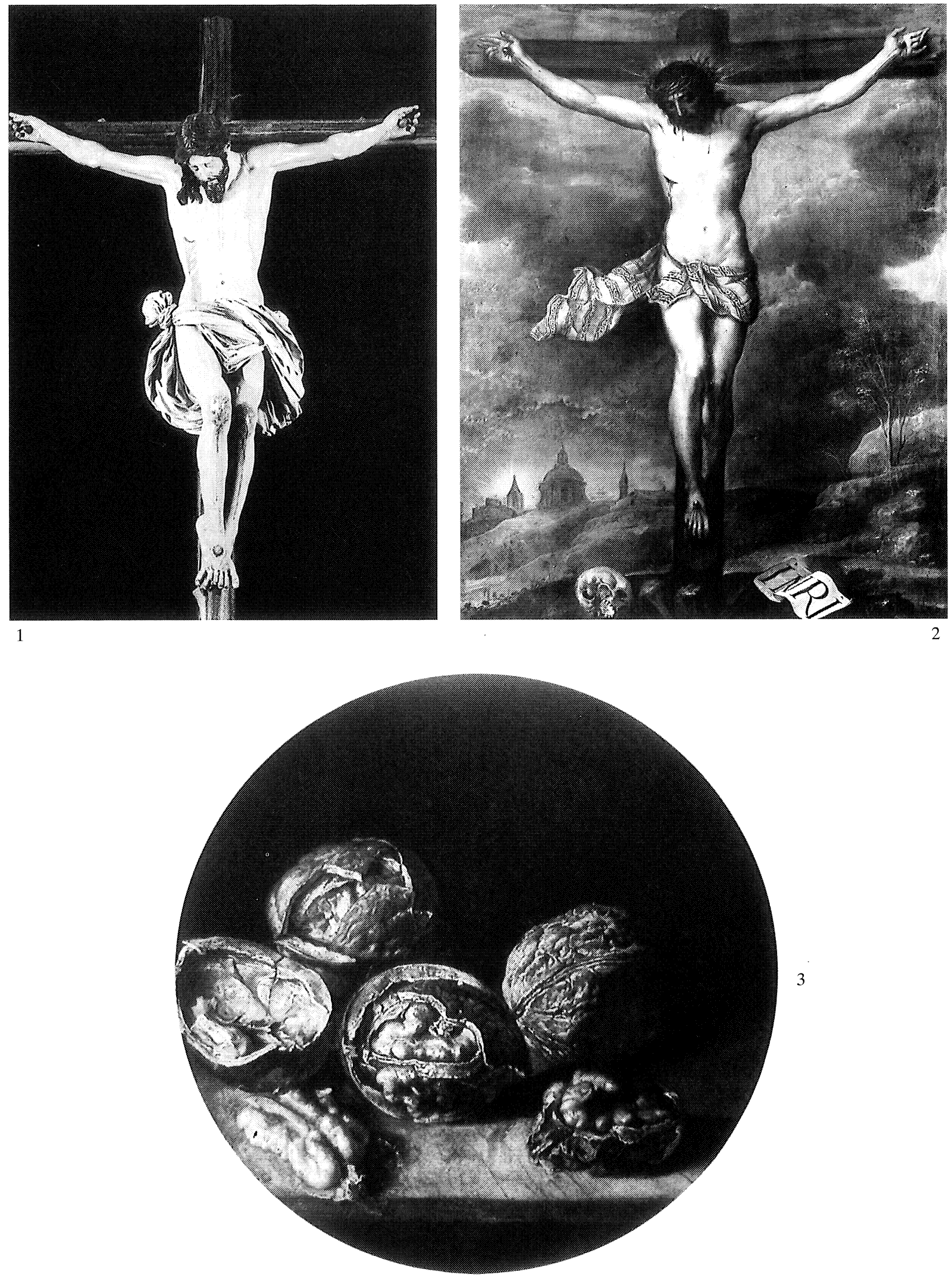

Fig. 1. Juan de Mesa, Cristo de la Buena Muerte. Madrid, Catedral (ca. 1621).

Fig. 2. Antonio de Pereda, Cristo Crucificado. Madrid, Colegio de San Ildefonso (1652).

Fig. 3. Antonio de Pereda, Bodegón de nueces. Bilbao, col. particular (1634). 
Es más, optó por un religioso como albacea testamentario, Fr. Antonio Pérez, prior del Convento del Carmen de Madrid, en el que se enterró. Incluso, a través de él, la protección de Crescenzi alcanzó al joven Pereda más allá de la muerte de su mentor. El albacea bien pudo favorecer el trabajo del artista en su orden, pues numerosos son los encargos de conventos carmelitas en los años posteriores.

\section{Otros mecenas. Objeciones a una idea}

Tras sus tempranos y prometedores escarceos cortesanos, a la sombra del Marqués de la Torre, tradicionalmente se viene achacando a la muerte de éste su exclusión de palacio. Procede la idea de la biografía que Lázaro Díaz del Valle hizo de él. Apuntaba el vallisoletano que aunque le faltó al mejor tiempo el amparo del Marqués, con la muerte que hurtó la hebra de sus esperanzas, no le desamparó la fortuna porque prosiguiendo sus estudios... fue tenido por uno de los más valientes artífices. Si se hace un análisis atento de la situación del Superintendente de Obras Reales en la corte, así como de los trabajos de Pereda tras su desaparición, se puede comprobar que el aserto es una verdad a medias.

Primero se ha supuesto, sin ningún fundamento, que entre Crescenzi y el Conde-Duque de Olivares existía enemistad por el control de las Obras Reales. Tal creencia choca con realidades como la comisión de obras a Crescenzi en las que directamente se implica Olivares, caso del Buen Retiro. O su relación con personajes de la órbita del Valido, como el consejero Tejada. Nada indica, por tanto, animadversión.

En cuanto a la producción pictórica de Pereda, es indudable que la falta de Crescenzi supuso un corte brusco de encargos directos de la corte, pero no un alejamiento definitivo. El problema de fondo se remite, creo, a cuestiones de gusto. Pereda resultaba idóneo para la imagen religiosa, no para el aparato palaciego ${ }^{17}$. Para empezar, se echa en falta retratos de su mano, género por excelencia de la propaganda regia. Los pocos temas profanos que se le conocen corresponden a su breve permanencia junto al Marqués, quien los propiciaría al hilo de los programas decorativos áulicos. Fue más un caso de selección que de arrinconamiento por motivos políticos.

Precisamente, cuando recobró la atención de la corte fue para encargos religiosos, como lo demuestran dos episodios sucesivos en la década de los 50. En 1650 firma la «Profesión de Sor Ana Margarita de Austria", para el convento de la Encarnación. Parece que, ya fuera indirectamente, Felipe IV tuvo a Pereda presente; aunque coincidiera con la ausencia de Velázquez, entonces en Italia. Que se pensara en él para realizar un exvoto conmemorativo del ingreso en clausura de la hija del Rey, no da a entender que la corte lo ignorara del todo. Como tampoco que el influyente Marqués de La Lapilla, Secretario del Despacho Universal, le encargara el retablo principal de su capilla sepulcral en el Colegio de Santo Tomás. En recompensa por su hermoso «Santo Domingo en Soriano», el satisfecho marqués hizo sentir su ascendiente en el Alcázar y otorgó al hijo del pintor el puesto de Ujier de Saleta. Menos espléndidos fueron los honorarios percibidos por el lienzo, exagerados por el autor del «Museo Pictórico» de forma interesada ${ }^{18}$.

$\mathrm{Al}$ margen de palacio, deben ser tenidos en cuenta los encargos para diversas casas nobiliarias, que merecen estudio más atento. Además del famoso caso del Almirante de Castilla, Pereda trabajó para el Cardenal Zapata, interesante eclesiástico en cuyo séquito llegó a España Giam-

17 Ya sugerido por D. Angulo; A. E. Pérez Sánchez, op. cit., p. 165.

18 Marqués del Saltillo: "La capilla de Santo Domingo Soriano en la iglesia del Convento de Santo Tomás», Revista de la Biblioteca, Archivo y Museo, 1946, pp. 233-267. M. ${ }^{a}$ Fernanda Puerta Rosell: "Aspectos artísticos de un patronazgo madrileño del siglo xviI. Don Fernando Ruiz de Contreras y la capilla de Santo Domingo en la iglesia del Convento de Santo Tomás", Actas VII Congreso CEHA, Murcia, 1988, pp. 351-357. 
battista Crescenzi ${ }^{19}$. A su muerte continuó sufragando el encargo, el retablo de la Iglesia madrileña de San Miguel, su hermano el Conde de Barajas. También tuvo relación con la familia Sandoval, ya que para su fundación de los Capuchinos de San Antonio del Prado Pereda pintó, en fecha imprecisa, el lienzo del altar mayor. El contacto con los herederos del Duque de Lerma pudo producirse bien a través de Zapata, que trajo de Italia el cuerpo de San Francisco de Borja para otra de las fundaciones de Lerma, la Casa Profesa de los Jesuitas, cuyo primer emplazamiento estuvo muy cerca de San Antonio. O bien por recomendación de los Capuchinos de Valladolid, para quienes pintó en 1640 los «Desposorios de la Virgen».

\section{La economía familiar: Los Bautrés}

Otro aspecto singular en Pereda es su aparente silencio ante el apartamiento de los cargos oficiales. Si fue la falta de Crescenzi el motivo del alejamiento, ¿por qué no conocemos algún memorial en el que haga constar sus méritos y medrar en el servicio real? La ausencia de las habituales peticiones de gracias o nombramientos, dan a entender una despreocupación nada común entre los pintores, siempre necesitados de gajes y empleos de la Corona.

Se puede encontrar explicación a esta postura en la buena demanda que tuvieran sus obras. Es decir, que sencillamente su posición se asentó lo bastante como para prescindir de la dependencia cortesana. Pero creo que tal independencia radicaba además en el sólido respaldo que representaba la familia de su primera mujer, en cuyos negocios se implicó.

Pereda casó en septiembre de 1635, a los seis meses de la desaparición de Crescenzi, con Mariana Bautrés, hija de un arquero de la Guardia de Corps. Aunque, la ocupación principal de Jacome Bautrés, fue la de encargado del abasto de cebada para Madrid. Las finanzas de los Bautrés estaban lo suficientemente saneadas como para, sobre el papel, dotar a su hija con la nada despreciable cantidad de 2.500 ducados. Disponemos de documentos referentes al comercio de cereal desde enero de 1644, cuando muerto el cabeza de familia es titular de los asientos su viuda, María de Cebrián; pero en dicha documentación se hace referencia a compromisos de pago desde 1634. El grano procedía especialmente de Estremera, pero también era suministrado por otras localidades de la vega del Tajo como Valderacete, Driebes, Mondéjar o Zarza de Tajo ${ }^{20}$.

La familia debía estar relacionada con los Duques de Pastrana, a cuyo señorío alcarreño pertenecían algunos de los lugares en los que se abastecía su negocio. Esto insinúa el legado que María de Cebrián, en un primer testamento dictado en 1645, de un calvario de marfil para la Duquesa doña Catalina Gómez de Sandoval en muestra de la boluntad y afecto que tengo de serbirla $^{21}$. De hecho, una de las hijas de Bautrés, María, casó con Pedro Jiménez, abogado de Pastrana. Como testamentarios nombró a sus yernos Antonio de Pereda y Jerónimo Rodríguez de Ocampo y al escribano Diego Navarro.

Ambos cuñados, Pereda y Ocampo, que era Mayordomo de Pobres de la madrileña Cárcel de Corte, se verían mezclados en los asuntos de María de Cebrián. En 1646 cada uno prestaba

19 Q. Aldea; T. Marín; J. Vives: Historia eclesiástica de España, vol. IV, Madrid, 1975, pp. 2803-2805. Peter Cherry: "La intervención de Juan Bautista Crescenzi y las pinturas de Antonio de Pereda en un retablo perdido (1634)", $A E A$, 1987, pp. 299-305.

20 Las transacciones, muy abundantes, no suelen ser de grandes cantidades. Se han localizado las del período $1644-$ 1650. Ver AHP: prots. 7.628 a 7.631. La primera en prot. 7.628, f. 1, requisitorias de pago de María de Cebrián y su nieta, Úrsula Ximénez (4-I-1644).

21 AHP: prot. 7.628, ff. 812-817. Testamento de María de Cebrián (19-IV-1645). 
3.000 reales a su suegra, seguramente con destino a sus asientos de cebada. $\mathrm{Al}$ año siguiente, los tres juntos daban poder a Lucas de Valdés para cobrar deudas a Jacinto Pérez ${ }^{22}$.

La situación del pintor empezó a trocarse paulatinamente en una mayor dependencia. Él, su mujer y su madre, María Salgado, vivían en las casas de la propia María de Cebrián, en la calle de la Magdalena. El precio del alquiler de los cuartos que ocupaban no aparece estipulado, aunque se otorgó carta de pago en la que su suegra se daba por satisfecha; hallándose Ocampo en idéntica situación ${ }^{23}$. Ese mismo día, en septiembre de 1647, Pereda consentía en prorrogar dos años más el pago de 1.000 ducados todavía pendientes de la dote de Mariana Bautrés y en prestarle 15.000 reales más ${ }^{24}$. La actividad del pintor vallisoletano como prestamista no se limitó al ámbito familiar, ya que en 1649 un tal Miguel Ruiz se comprometía a devolverle 12.000 reales; y al año siguiente suministró 1.500 ducados a don Bernardo de Ojeda, caballero de la Orden de Alcántara ${ }^{25}$. Las obligaciones de pago no incluían intereses, lo que no permite hablar con seguridad de negocio, pero advierten del saludable estado de las cuentas de Pereda en este período, o bien que hiciera gestiones por cuenta ajena.

En 1650 el entramado familiar se complicó, ya que el alquiler de sus habitaciones fue traspasado a su cuñado Jerónimo, que figura como propietario de las mismas ${ }^{26}$. Pereda pagaba a partir de entonces 1.000 reales anuales por dos quartos altos..., una sala grande en baxo... y un aposento nuebo que sale al patio con un sibil en la cueba y seruicio de poço. Años después acabaría como dueño de las casas. Finalmente, el pintor se mezcló de lleno en los negocios de María Cebrián, ya que en los meses finales de 1650 realizó sendas transacciones de cebada con vecinos de Estremera y Valderacete ${ }^{27}$. En 1651 prosiguió con sus operaciones dinerarias, contrayendo una deuda con el presbítero Sebastián Muñoz (1.104 reales) y a su vez prestando al pintor Lorenzo de Soto (2.200 reales) ${ }^{28}$; dato este que pone en relación a ambos artistas, al menos en el plano comercial.

Ante este panorama, encontramos a un Pereda inmerso por completo en el engranaje económico de su familia política, por lo menos en la breve etapa que se ha podido documentar de 1646 a 1651. Aunque ocasionalmente invirtiera en ellos las ganancias que diera la pintura, es evidente que los estrechos vínculos con los Bautrés supusieron un sólido respaldo. Fuese causa o consecuencia, lo cierto es que las finanzas del pintor debían atravesar un buen momento. Por ejemplo, a fines de 1651 concurría, como numerosos colegas, a la almoneda del pintor Domingo Guerra Coronel, adquiriendo algunas pinturas y engrosando su biblioteca con seis libros pequeños ${ }^{29}$.

\section{El hijo pintor: Joaquín de Pereda}

María de Cebrián, la emprendedora suegra de Pereda, moría en 1660. Es de supomer que en los diez años que median desde las últimas noticias, mantuviera su lucrativo negocio. En su último y definitivo testamento (1658) ${ }^{30}$, hizo mención de cada uno de sus nietos, sólo figurando

22 AHP: prot. 7.629, ff. 122-123. Obligaciones de María Cebrián a Pereda y Jerónimo Rodríguez de Ocampo (18IV-1646). Id. prot., f. 724. Poder para cobrar a Lucas de Valdés (23-VIII-1647).

23 AHP: prot. 7.629, f. 762 (11-IX-1647); f. 780 (17-IX-1647).

24 AHP: prot. 7.629, ff. 768 y 770-771 (11-IX-1647).

25 AHP: prot. 7.630, f. 1.078 (15-XII-1649); prot. 7.631, f. 226 (13-V-1650)

26 AHP: prot. 7.631, f. 19 (13-I-1650).

27 AHP: prot. 7.631, f. 408 (5-IX-1650); f. 430 (21-XI-1650).

28 AHP: prot. 7.631, f. 733 (12-VI-1651); f. 811 (11-VIII-1651)

${ }_{29}$ Marqués del Saltillo: «Un pintor desconocido del siglo xviI: Domingo Guerra Coronel», Arte Español, 1944-45, pp. 43-48. Saltillo omite la compra de los libros, ver AHP: prot. 6.766, f. 551

${ }^{30}$ AHP: prot. 6.535, ff. 267-272 (19-V-1658). Nombró testamentarios a Pereda, Ocampo y Juan de San Martín, marido de una de sus nietas. 
Joaquín como hijo de Pereda. Por tanto Teresa, la otra hija habida por el matrimonio, ya había fallecido antes de 1658.

Joaquín Antonio de Pereda, el único hijo superviviente del pintor, mantuvo una tormentosa relación con su padre, protagonizada por continuos enfrentamientos que acabarían por tener la herencia materna de fondo. Los roces tuvieron su inicio con la fuga del joven del hogar paterno con una criada, a Castrejón (Valladolid). De la aventura nació una niña, Antonia, de la cual se dice en 1676 , en el testamento de Joaquín ${ }^{31}$, que tiene unos quince años. Por tanto, el «incidenter tuvo lugar hacia 1661.

Pereda logró que su hijo regresara a Madrid, y entre las razones para convencerlo pudo haber influido la interinidad en la plaza de Ujier de Saleta, que precisamente se le concedió en 1661. Poco después, en 1664, Joaquín casaba con Tomasa de Olmedo ${ }^{32}$. En las capitulaciones matrimoniales previas ${ }^{33}$, consta que Tomasa entonces era huérfana y actuaba como su tutor Matías Colomo. La novia aportaba como dote toda la herencia recibida de sus padres, Juan de Olmedo y Josefa Joque de la Cruz: 8.000 ducados fruto de la venta de unas casas en la Plaza Mayor y prebendas de memorias de diversa cuantía (poco más de 200 ducados). Era pues una mujer con un capital medio, que Antonio pudo ver conveniente para su hijo. Joaquín ofreció sus derechos de gajes y casa de aposento como aumento de dote. Y a la vez, Pereda padre se comprometía a donar a la pareja diez años de ocupación de casa y 500 ducados. Además, traspasaba a su hijo una deuda pendiente con los herederos de Miguel Ruiz, propietario de unas casas en la calle del Olivar. Esta deuda no se conseguiría saldar hasta diez años después, en la que se produce la venta judicial de los bienes de Ruiz ${ }^{34}$. Menos se tardó en hacer efectivos los bienes de Tomasa, que empezaban a liquidarse inmediatamente ${ }^{35}$.

Los problemas no afloraron hasta el fallecimiento de Mariana Bautrés en noviembre de $1673^{36}$. Dos años más tarde Joaquín había interpuesto a su padre pleito por incumplimiento de una cláusula testamentaria de su madre, referente a la fundación de unas memorias ${ }^{37}$. Para entonces Antonio había contraído segundas nupcias con Mariana Pérez, una viuda de posición acomodada, complicando más el problema de la hacienda. Lo cierto es que Pereda no realizó la pertinente partición con su hijo, más que necesaria habiéndose vuelto a casar, y además éste le acusaba de haber ocultado bienes en el inventario. El litigio se agudizó hasta el punto de que Pereda ingresó en prisión, a instancias del Fiscal de Obras Pías ${ }^{38}$. Finalmente se solucionó el asunto al morir Joaquín el 2 de octubre de 1676, y ser su padre el heredero forzoso ${ }^{39}$. Sin embargo, Joaquín no le escatimó reproches ni en sus últimas voluntades, reclamando a Antonio los 500 ducados prometidos en su boda. Aun así, le deja encomendada a su hija, Antonia, a la que no nombra heredera, sino al propio Antonio de Pereda y a Tomasa de Olmedo ${ }^{40}$.

El «hijo díscolo», que tantos quebrantos supuso a un Pereda que tampoco pecaba de cando-

${ }^{31}$ Mercedes Agulló; M. ${ }^{a}$ Teresa Baratech: Documentos para la historia de la pintura española. II, Madrid, 1996, pp. 88-91.

32 Matías Fernández: Parroquia madrileña de San Sebastián. Algunos personajes de su archivo, Madrid, 1995, p. 181.

33 AHP: prot. 10.534, ff. 95-98 (17-VIII-1664).

34 AHP: prot. 10.611, ff. 223-446 (20-VI-1674). Jerónimo de Ocampo, testamentario de Miguel Ruiz, figura con Joaquín como acreedor.

35 AHP: Prot. 10.534, ff. 99-100, cartas de pago de Joaquín Pereda a Sebastián Muñoz, presbítero (25-VIII-1664); f. 101, carta de pago a Juan Ruiz de la Plaza, mercader (25-VIII-1664); f. 135, carta de pago a D. Pedro de Urijas, de la Congregación del Salvador (6-X-1664). En las tres primeras figura Antonio de Pereda como testigo.

${ }_{36}$ M. Fernández, op. cit., p. 181.

37 M. Agulló; M. T. Baratech, op. cit., p. 87.

38 AHP: prot. 11.425, f. 587. Acuerdo entre Tomasa de Olmedo y Mariana Pérez (5-VI-1678).

39 Archivo Parroquial de San Sebastián, Madrid. Libro 14 Difuntos, ff. 88v-89 (2-X-1676).

${ }^{40}$ M. Agulló; M. T. Baratech, op. cit., p. 90. 
roso, no sólo ejercía como Ujier en Palacio, era además pintor. Como tal se titula en la tasación que realiza de las pinturas de Manuel de Moya, poco antes de morir ${ }^{41}$. Y en su testamento declaraba estar pintando un santo christo de la misericordia... para Don Pedro de Trapada, oficial de la presidencia de hazienda. Ambos oficios, artesanal y palaciego, se los debía a su padre. Su presencia en el obrador paterno, así como su posterior independización, deben ser tenidos en consideración a la hora de futuras valoraciones de la obra tardía de Pereda. Joaquín pasa, junto a la reciente incorporación del aragonés Pedro de Aybar ${ }^{42}$, a engrosar la lista de sus discípulos junto a Alonso del Arco, Teodoro Ardemans o los desconocidos Pedro de Robles y Juan Francisco de Aragón. Su período productivo abarcaría aproximadamente de 1650 a 1676.

De la actividad paterna, sólo aportar noticia de dos tasaciones, realizadas por los años de la «riña de los Pereda». Al inicio de 1673 valoró las pinturas de María Díaz, mujer de Roque Cejudo; y en 1676, las dejadas por el platero Mateo Esteban ${ }^{43}$.

\section{La herencia de Antonio de Pereda}

Pereda sobrevivió algo más de un año a su hijo, sin haber solucionado el embrollado asunto de su herencia. Horas antes de fallecer, el 29 de enero de 1678, redactó un codicilo inédito hasta ahora, en el que hacía pequeñas modificaciones a su testamento: añadía un nuevo albacea, Manuel Sánchez de Arce, y retocaba las mandas a sus criadas ${ }^{44}$. El documento tiene más valor informando de algunas obras de Pereda y sus destinatarios. Así, D. Mateo de Fonseca le había encargado cinco lienzos, de tema no determinado, por los que le había adelantado cien ducados. $\mathrm{Al}$ no poder concluir el trabajo, ordenó que se devolvieran las telas vajando lo q. huv echo en uno dellos. Pero D. Mateo no salió de vacío, ya que Pereda, por la amistad tenida con él, le donó a cambio vn $s^{n}$ Fran $^{c o}$ q. tiene del Ticiano. Lo mismo le ocurrió a Juan Francisco Melgar, a quien había hecho promesa de pintar una Inmaculada y compensa con vn quadro de nra. $S^{a}$ de la Soledad q. $t^{e}$ en su alcoba y que es de su mano.

Sin duda, el dato más curioso es el concerniente a las obras que le encargó Alonso de la Encina: $y$ le tengo hecho quatro Reyes que no me tiene satisfho. Y una turca que retoqué en una sta $\mathrm{Ca}-$ talina. El hecho es buena muestra de las tareas que a veces se solicitaban de los pintores, como el «rehacer» otras obras; tanto como del criterio generalizado en los españoles del momento, que preferían colgar en sus casas una santa, antes que una imagen profana, por muy hermosa que fuera la turca representada. Concluyó esta pequeña adición testamentaria con reclamaciones a deudores, caso de D. Francisco de Sandoval (por una lámina del «Desengaño», un San Jerónimo, un San Juan y una Inmaculada, inconclusa) y D. Juan Pulido (me deue el adereço de unas caueças de láminas). Pese a tanto detalle, nada nuevo dejó dispuesto acerca de la herencia.

Sus bienes, los de su primera mujer y los pertenecientes a Joaquín permanecían indivisos, con lo que legaba a sus herederos una situación muy problemática. La herencia se debía presentar bastante jugosa, a juzgar por el aire señoril que Palomino dice se daba Mariana Pérez. Sus testamentarios, su viuda y la de Joaquín emprendieron de inmediato los trámites necesarios para desenmarañar tal enredo patrimonial, siempre intentando sacar el mejor partido. La tasación de los bienes y su almoneda, diligencias todavía por localizar, se empezaron con celeridad, pues en

41 AHP: prot. 10.359, s.f. (13-VIII-1676).

42 M. Agulló; M. T. Baratech, op. cit., p. 85. Acerca de Aybar véase Alfonso E. Pérez Sánchez: Pintura barroca en España. 1600-1750, Madrid, 1992, p. 399.

43 AHP: prot. 10.329, f. 134 (27-II-1673); prot. 8.181, s.f. (28-II-1676).

${ }_{44}$ AHP: prot. 8.698, ff. 547-548 (29-I-1678). 
el mes de mayo Mariana Pérez recibía diferentes cantidades de ella ${ }^{45}$. Para evitar prolongar innecesariamente un proceso que acabaría por consumir el remanente, las viudas de los Pereda firmaron un acuerdo para repartirse la hacienda, que se empezó a materializar ${ }^{46}$.

No obstante, el convenio se rompió al comprobar la viuda de Joaquín que se le estaban ocultando objetos de la testamentaría. En concreto halló un Niño de bronce dorado sobre un óbalo o mundo de piedra ágata sobre una peana de hébano negra ${ }^{47}$ sacado de los bienes de su suegro. El asunto persistía en 1681, ya que Mariana Pérez otorgó ese año un poder para defenderse de las alegaciones de la Olmedo ${ }^{48}$. Y aun en 1698, en las disposiciones testamentarias de la viuda de Pereda, quedaba pendiente de solución ${ }^{49}$. La paradoja es que finalmente la hija ilegítima de Joaquín, Antonia, quedaba como heredera de todos los bienes correspondientes a su abuelo. Si algo podemos entresacar de los textos, es que la situación económica de Mariana Pérez no era entonces muy holgada, ya que muchas de las mandas son referentes a efectos empeñados y otras a la fundación de patronatos de Mariana Bautrés (en la Iglesia de la Virgen de Loreto) y de Pereda (San Lorenzo de Valladolid) aún por cumplir, seguramente por falta de recursos. De hecho la capellanía vallisoletana aun no se había fundado en $1704{ }^{50}$. Parece cierto, pues, el comentario de Palomino al atestiguar que alcanzó a ver a la viuda de Pereda en suma miseria.

De la relación de empeños que detalla el primer codicilo de su viuda, algo se puede reconstruir acerca de los bienes que formaron el patrimonio de Pereda, destacando que la mayor parte de los objetos en préstamo son esculturas. Es el caso de las que mantenían en su poder Agustina de Valencia (Vna hechura de santo Domingo de piedra de pórfido... y una cabeza de ${ }^{n}$ Juan Bauptis${ }^{\text {ta }}$ de barro cozido), el escribano Alonso Martínez (Vn santo xpto. de bronze y oro molido con su cruz de hébano) o Juan Díaz de la Calle, caballero de Santiago y Oficial Mayor de la Tesorería de Indias (Vna hechura de $s^{n}$ Juan y otra de $s^{n}$ Pedro de alabastro). A estas se suma el mencionado Niño de bronce, distraído de la testamentaría. Tal vez fuesen las estatuas que Crescenzi regaló a su protegido, o muestra del ya sugerido interés de Pereda por la escultura. Que fueran objeto principal de empeño, es debido a su mayor valor frente a los cuadros, por el material en que están realizadas.

En cuanto a las pinturas, el citado Juan Díaz tenía además vna pintura pequeña del desengaño y Eugenio Delgado, vecino de la Carrera de San Francisco, guardaba vn quadro grande del desengaño. Estos desengaños son versiones del «Desengaño de la Vida», forma en que son conocidas las Vanitas en el Siglo de Oro. La decepción del tiempo y la inutilidad de las soberbias mundanas, como ya se ha visto, son asuntos sustanciales a la producción de Pereda. Estas noticias, sin olvidar la ya referida a Francisco de Sandoval, vienen a confirmar que el tema le era demandado asiduamente desde sus primeros años ${ }^{51}$. Incluso, creo que se puede identificar el cuadro depositado en casa de Delgado, con el ejemplar conservado en los Uffizi (Fig. 5), que ya ha sido rela-

45 AHP: prot. 11.425, ff. 330-301. Poderes de Juan Álvarez, Manuel Sánchez de Arce, Alonso Martínez y Mariana Pérez de Pereda para concluir el juicio de particiones pendiente (8-II-1678). Id. prot. f. 383. Carta de pago de Mariana Pérez a Alonso Martínez (31-V-1678).

46 AHP: prot. 11.425, ff. 384-395. Este interesante documento especifica las etapas por las que atravesó el pleito familiar (5-VI-1678). Id. prot., f. 396 (20-VI-1678) y f. 500 (8-XI-1678). Cartas de pago de Tomasa de Olmedo.

47 M. Agulló; M. T. Baratech, op. cit., p. 91.

48 AHP: prot. 8.698, f. 800 (22-I-1681).

49 AHP: prot. 13.849, ff. 198-199, testamento de Mariana Pérez (12-IV-1698). Id. prot., f. 200. Codicilo (28-VI1698). Prot. 11.057, ff. 377-378, codicilo y declaración (20-VI-1698). Prot. 13.849, ff. 227-228, Fideicomisaría de los bienes de Mariana Pérez, por Alonso Martínez (2-VII- 1698).

50 José Martí y Monsó: Estudios histórico-artísticos relativos principalmente a Valladolid, Valladolid, 1898-1901, pp. 570-571. Jesús Urrea: "Notas vallisoletanas. Archivos parroquiales", Boletín del Seminario de Estudios de Arte y Arqueología, 1971, pp. 515-517.

51 William B. Jordan; Peter Cherry: Spanish Still Life from Velázquez to Goya, London, National Gallery, 1995 , p. 84. 
cionado con el que Antonio Palomino vio en manos de los descendientes del pintor ${ }^{52}$. De hecho, en el testamento de Delgado aclara cómo llego a él y algo sobre la temática: ... quedó en mi poder un quadro del Juicio q. se tasó por Claudio Coello en doszientos ducados de vellón, el qual quadro le tenía el dho. Manuel González de empeño de duzientos ducados q. sobre él dio a D. Ant ${ }^{o}$ Pereda... ${ }^{53}$ Se puede observar que en el ejemplar de Florencia figura, al lado izquierdo, una escena del Juicio Final; de ahí que fuera también citado como «Juicio». Por la anotación testamentaria de este desconocido, se puede deducir que fue Claudio Coello quien tasó la colección de Pereda a su muerte. Este pudo ser el contacto inicial entre Teodoro Ardemans y Coello, huérfano entonces de maestro, que acabaría con su paso al taller del madrileño.

\section{El pintor iletrado. Algunas conclusiones}

Del testamento de Mariana Pérez podemos incluso entresacar dos títulos de la célebre biblioteca del pintor. Entre otros objetos que el teniente de cura de San Andrés, Antonio Padilla, tenía en depósito, figuraban vn libro de la nobleza de Andaluzía y otro de Materias de Morante... de la herenzia del dho. $D^{n}$ Antonio de pereda ${ }^{54}$. No deja de ser irónico que la última fuera una de las obras de Pedro Díaz Morante, eminente calígrafo e inventor de un innovador método de aprendizaje de escritura, profesor de discípulos ilustres como el Cardenal Infante D. Fernando, el Condestable de Castilla y el primogénito del conde de Barajas ${ }^{55}$. Ya vimos que Pereda había tenido trato directo con el conde y su hermano el Cardenal Zapata, por lo que se estrecha más el vínculo en torno al prelado.

Que se trata de Morante es más que probable, pues se conocen cartas del hijo y homónimo de éste dirigidas al pintor ${ }^{56}$. Y el dato resulta más chocante, si lo que se pretende confirmar es que Antonio de Pereda era analfabeto. Creo en efecto que a Pereda le leían libros y cartas terceras personas. La posesión de una biblioteca no siempre significa su lectura. Y, a falta de un conocimiento preciso de la suya, poniéndonos en caso extremo, Pereda bien pudo tener muchos libros... tan sólo por sus estampas. Como ejemplo tenemos la «Nobleza de Andalucía", libro heráldico profusamente ilustrado. Por otra parte, cuesta trabajo creer que un poseedor de la elegante cartilla de aprendizaje de Morante, que hubiera practicado la airosa caligrafía de sus planas, fuera capaz de hacer tan torpes y diferentes firmas a lo largo de su vida (Figs. 6 a 10).

Incluso pudo influir su carencia de letras para frustrar su carrera oficial. Obtuvo para Joaquín la plaza de Ujier, que no para si mismo, porque su hijo tenía la educación apropiada. Contradirían esta teoría tanto los círculos cultos que le acogieron a su llegada a Madrid, como la carta que envió a Díaz del Valle. No sabemos hasta que punto Crescenzi, a pesar de su procedencia italiana, se preocupó de incentivar algo más que las habilidades manuales de alguien que consideraba «su criado"; o de la posible renuencia de Antonio a aprender. En cuanto a la breve nota a su paisano, es evidente que firma y texto son de manos distintas ${ }^{57}$.

52 Alfonso E. Pérez Sánchez: D. Antonio de Pereda (1611-1678) y la pintura madrileña de su tiempo, Madrid, 1978, cat..$^{\circ} 7$.

53 AHP: prot. 12.282, ff. 454-458. Testamento de Eugenio Delgado (1-X-1695).

54 Gonzalo Argote de Molina: Nobleza de Andalucía, Sevilla, 1588. Pedro Díaz Morante: Nueva arte donde se desentierran las ignorancias que hasta oy ha avido en enseñar a escrivir, Madrid, Luis Sánchez, 1616. A ésta sucedieron tres partes más, publicadas sucesivamente en 1624, 1629 y 1631, algunas de ellas con reimpresiones posteriores a lo largo del siglo.

55 Emilio Cotarelo Mori: Diccionario biográfico y bibliográfico de caligrafos españoles, vol. II, Madrid, 1916, pp. 43-80.

56 E. Cotarelo, op. cit., pp. 82-83.

57 J. Martí y Monsó, op. cit., pp. 571-573. D. Angulo; A. E. Pérez Sánchez, op. cit., p. 149. 


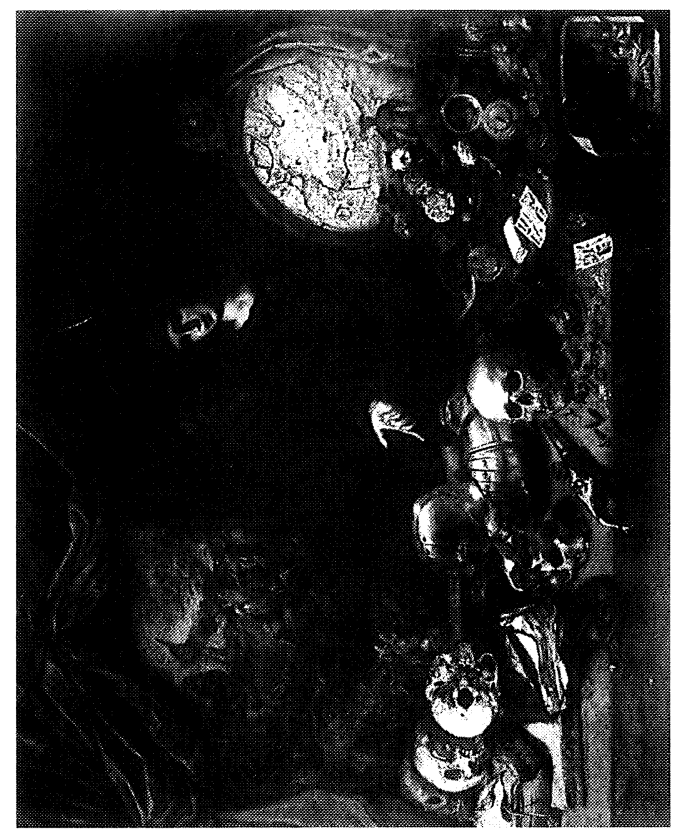

in

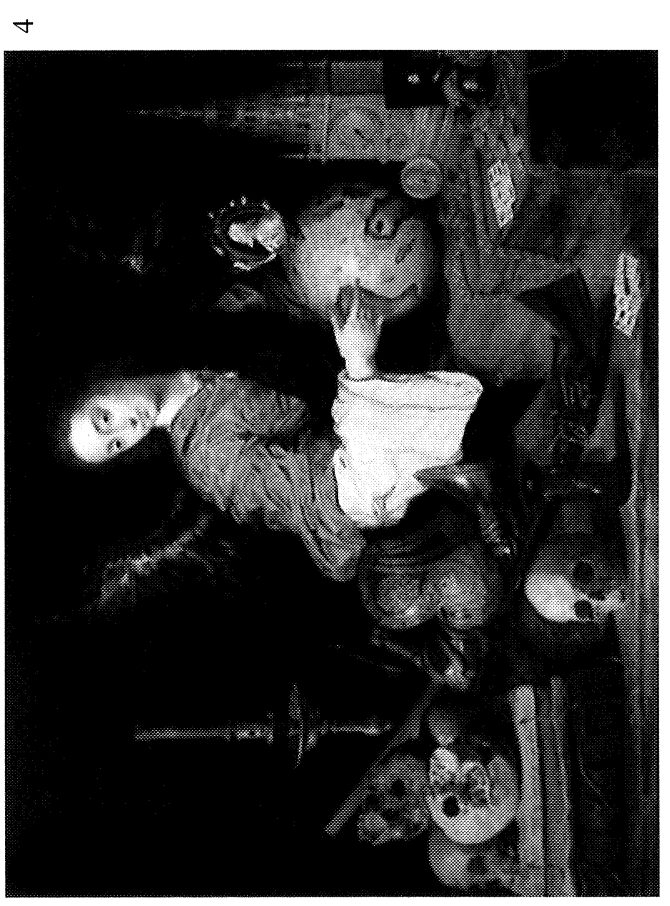

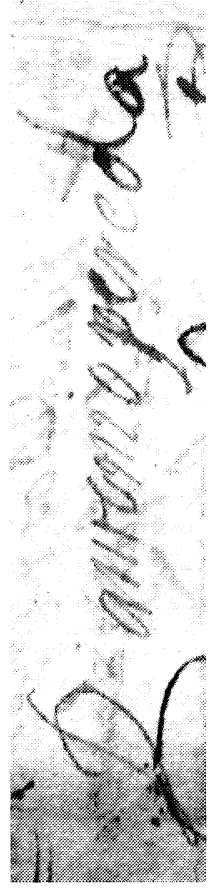

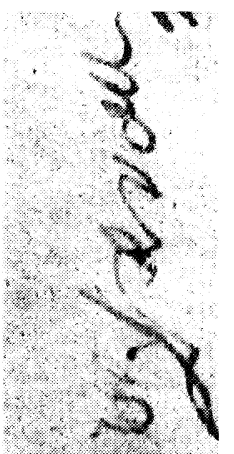

으

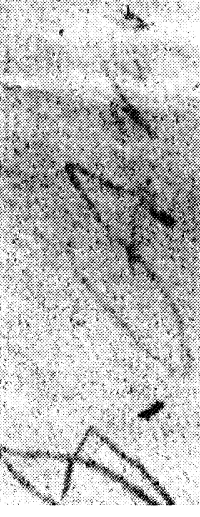

豖

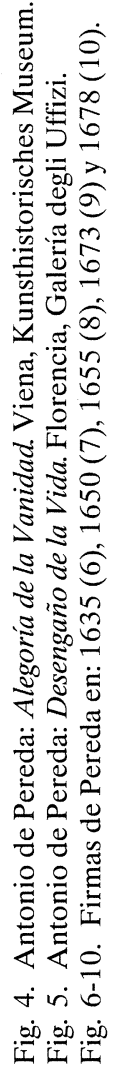

$r$

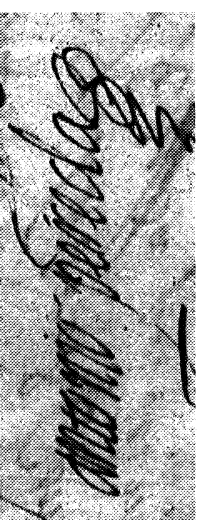

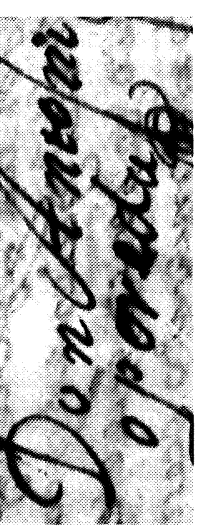

$\infty$
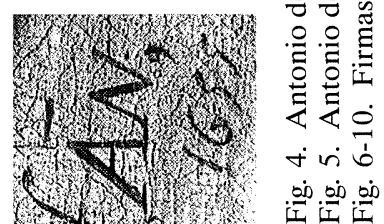
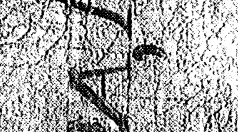

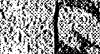

W.1.
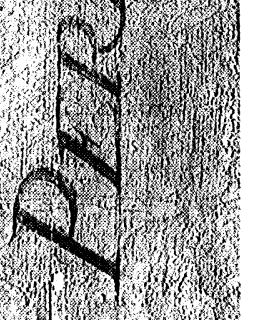
Pereda fue un analfabeto excepcional, por su maestría en el oficio. Pero no se puede asegurar que fuera una excepción en su profesión. Desde luego a Palomino le parecía cosa indigna, pero el juicio viene de un erudito. En la España del siglo xvII el analfabetismo en las ciudades, donde se concentran los pintores, rondaba el $60-50 \%$ de su población ${ }^{58}$. En el caso concreto de los pintores, sólo disponemos de los inventarios de sus bibliotecas, que han de ser valorados con la prevención ya apuntada. Pero, no por ello se debe imponer un criterio reductivo y dudar sistemáticamente de las librerías. Por tanto, a la espera de un estudio cuantitativo concluyente, habrá que extrapolar los valores generales de la sociedad urbana del Seiscientos y cifrar en un salomónico $50 \%$ el analfabetismo de los pintores. Serían los que trabajaban a cobijo del Alcázar, los artistas de importancia, los que gozarían más ampliamente del privilegio de la lectura.

Que se carezca prácticamente de noticias contemporáneas sobre el asunto es del todo lógico. Cuando la dignidad de la pintura era el caballo de batalla de la tratadística de arte, resultaba un baldón difícilmente excusable señalar que la mitad de los pintores trabajaba desde la ignorancia. En ese grupo, extraordinario por su personalidad, entraría Pereda. Éste, como un retruécano más, no tendría empacho en participar en los pleitos con la Cofradía de los Siete Dolores.

En lo demás, Antonio de Pereda combinó negocios y pintura, en una forma nada extraña a colegas suyos como Camilo o el propio Velázquez, que también buscaron ingresos fuera de los pinceles, aunque por otras vías. Sus signos diferenciadores están en sus obras. En su personal y persistente forma de interpretar con precisión la realidad que sus contemporáneos, de los que fue a remolque, querían diluir y «hacer flotar».

58 C. Larquié: «La alfabetización de los madrileños en 1650», Anales del Instituto de Estudios Madrileños, 1980, pp. 223-252. 